\title{
Southern Oscillation Index and transmission of the Barmah Forest virus infection in Queensland, Australia
}

\author{
Peng Bi, Shilu Tong, Ken Donald, Kevin Parton, Jack Hobbs
}

El Niño-Southern Oscillation (ENSO) events are usually accompanied by changes in the trade winds, cloud amounts and rainfall over the tropical Pacific and Australian regions, and seem to be related to many climatic anomalies around the globe. A measure of ENSO is the Southern Oscillation Index (SOI), which is the normalised atmospheric pressure difference between Tahiti in the south Pacific and Darwin in northern Australia. The SOI is closely related to variations in temperature and rainfall across the Pacific and in eastern Australia. ${ }^{1}$ A positive index (low pressure at Darwin, greater rainfall, higher sea levels) means that the south eastern trade winds feed moisture across the Pacific towards the Australian region. Hence positive SOI values would tend to favour salt marsh mosquito breeding, ${ }^{2}$ and as a consequence might impact on the transmission of some mosquito borne diseases such as the Ross River virus infection. ${ }^{3}$

Barmah Forest virus (BFV) infection, charac-

Department of Socia

and Preventive

Medicine, the

University of

Queensland, Brisbane,

Australia

$\mathrm{PBi}$

K Donald

School of Public

Health, Queensland

University of

Technology, Brisbane,

Australia

S Tong

Department of

Agricultural

Economics and

Business, University of

Guelph, Canada

K Parton

School of Human and

Environmental

Studies, the University

of New England,

Armidale, Australia

J Hobbs

Correspondence to:

Dr S Tong

Accepted for publication 10 June 1999 terised by polyarthritis, myalgia, rash, fever, lethargy and malaise, is caused by an alphavirus, with Aedes and Cules mosquitoes as major vectors and marsupials as suspected host. The incubation period may be 7-9 days, the rash lasts an average of seven days and BFV infection may also lead to chronic illness in some patients. ${ }^{4}$ It has been regarded as one of the most important arbovirus diseases in the Australasian region and recently emerged as an increasing cause of human disease in mainland, Australia. ${ }^{2}$ In Australia, most BFV infections occur in Queensland with a tropical and sub-tropical climate. In 1996, for example, $68.8 \%$ of the BFV cases were developed in Queensland and the incidence was as high as 15.93/100 $000 .^{5}$

\section{Methods}

To quantify the relation between the SOI and the monthly incidence of notified BFV infection in Queensland, Spearman's rank correlation analysis was conducted using data collected for the period of 1992-1996 supplied by the Queensland Department of Health. The Australian Bureau of Meteorology provided SOI values. The population data were retrieved from the Australian Bureau of Statistics.

\section{Results}

The results showed that there was a significant correlation between the monthly incidence of the BFV infections and the SOI values of the current month, and the previous two, three and four months, while the three month lagged effect was the most significant $(r=0.42$, $\mathrm{p}=0.001$ ) (see fig 1 ).

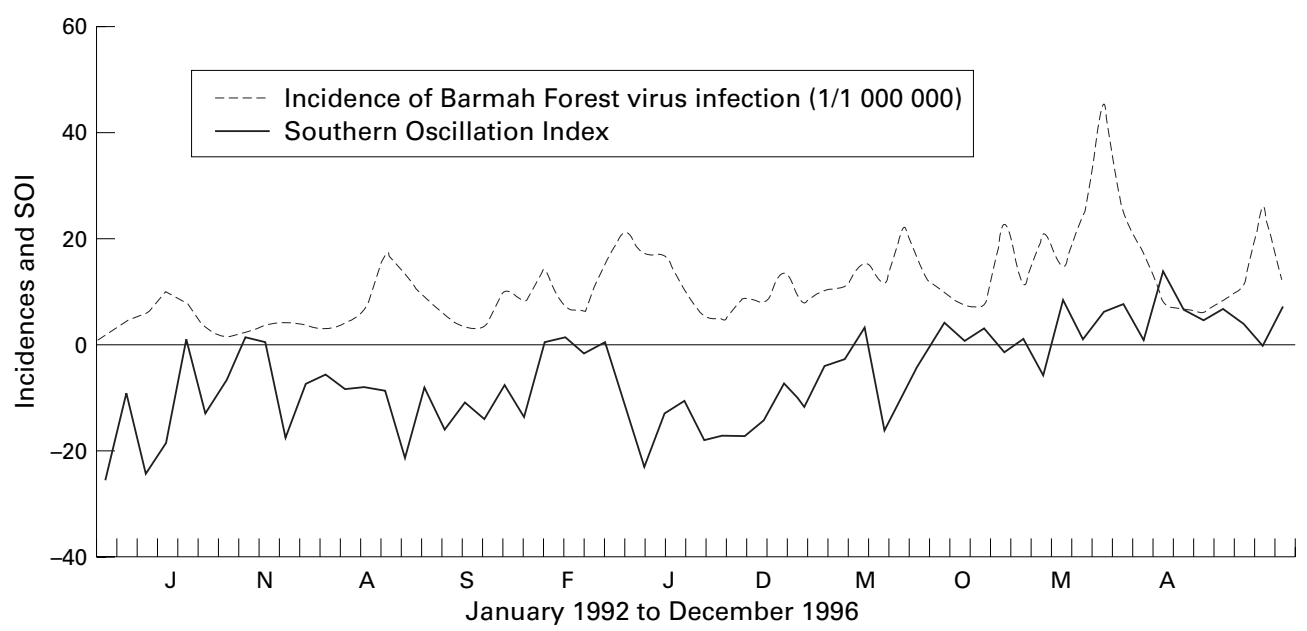

Figure 1 The monthly incidences of BFV infection and the Southern Oscillation Index in Queensland, Australia, 1992-96. 


\section{Discussion}

The result is consistent with similar studies on other mosquito borne diseases ${ }^{23}$ and is biologically plausible, as the mosquitoes that transmit the $\mathrm{BFV}$ are sensitive to temperature and rainfall. ${ }^{1}$ Also positive SOI values are associated with a rise of sea level, which had a positive impact on the breeding of some Aedes. ${ }^{2}$ Other social factors might also influence the transmission of the BFV infection. However, the records in the Queensland Department of Health show there was no abrupt change in the level of mosquito control measures and no large influx of infected or non-immune people by immigration during the study period, so variations in the incidence of the disease may have been mainly climate related. The finding suggests that the SOI warrant further investigation as a predictor of BFV infection. Also, if climate change continues towards wetter in most regions and warmer in whole Australian region as predicted by CSIRO,${ }^{6}$ the $\mathrm{BFV}$ infection will be an increasing public health problem in mainland Australia, and possibly in the wider Australasian region.

Conflicts of interest: none.

1 Nicholls N. El Nino-Southern Oscillation and vector-borne disease. Lancet 1993;342:1284-5.

2 Lindsay M, Mackenzie J. Vector-borne diseases and climate change in the Australasian region: major concerns and the public health response. In: Curson P, Guest C, Jackson E, eds. Climate change and human health in the Asia-Pacific region. Canberra: Greenpeace, 1998: 47-62.

3 Tong SL, Bi P, Parton KA, et al. Climate variability and transmission of epidemic polyarthritis. Lancet 1998; 351:1100.

4 Flexman JP, Smith DW, Fraser JRE, et al. A Comparison of the diseases caused by Ross River virus and Barmah Forest virus. Med F Austr 1998;169:159-63.

5 Curran M, Harvey B, Crerar S, et al. Australia's notifiable disease status, 1996: annual report of the National Notifidisease status, 1996: annual report of the National Notifi-
able Diseases Surveillance System. Communicable Diseases able Diseases Surveillance Sy

6 CSIRO. Climate change scenarios for the Australian region. Melbourne: CSIRO Division of Atmospheric Research, 1996. 